\title{
Endothelin-A Receptor Blockade Prevents and Partially Reverses Neonatal Hypoxic Pulmonary Vascular Remodeling
}

\author{
NAMASIVAYAM AMBALAVANAN, ARLENE BULGER, JOANNE MURPHY-ULLRICH, \\ SUZANNE OPARIL, AND YIU-FAI CHEN
}

Department of Pediatrics [N.A., A.B.], Department of Pathology [J.M.U.], Department of Medicine

[S.O. Y.-F.C.], University of Alabama at Birmingham, Birmingham, Alabama, 35233

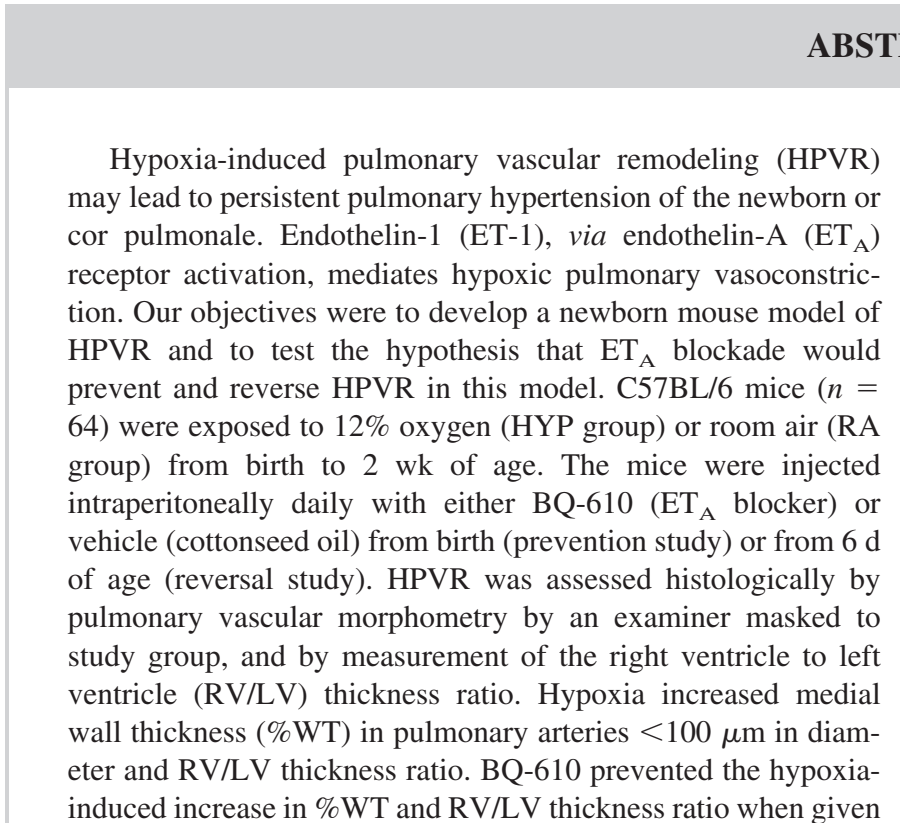

In human neonates, chronic hypoxemia increases muscularity of the pulmonary arteries and extends muscularity to more distal arteries (1). Fetal (2) and neonatal $(3,4)$ hypoxemia also leads to pulmonary vascular remodeling in animal models. This pulmonary vascular remodeling may predispose to pulmonary vasoconstriction and PPHN in response to normal changes in oxygenation and acid-base status occurring during labor and early neonatal life. PPHN affects more than 10,000 infants every year in the United States (5) and is associated

Received March 4, 2004; accepted September 3, 2004.

Correspondence: Namasivayam Ambalavanan, M.D., 525 New Hillman Bldg., University of Alabama at Birmingham, 619 South 20th St., Birmingham, AL 35249; e-mail: ambal@uab.edu

Funded in part by National Heart, Lung, and Blood Institute Grants HL-44195, HL-50147, HL-45990, HL-07457, HL-56046; National Institute of Child Health and Human Development grant K08 HD046513; and a Child Health Research Center Grant through NICHHD P30HD28831.

Presented in part at the meeting of the Pediatric Academic Societies' Annual Meeting, Seattle, WA, 2003.

DOI: 10.1203/01.PDR.0000159512.55862.69 from birth, and later therapy partially reversed the hypoxiainduced increase in \%WT but not RV/LV thickness ratio. These data show that in the newborn mouse model, chronic hypoxia leads to HPVR that can be completely prevented and partially reversed by $\mathrm{ET}_{\mathrm{A}}$ blockade. These results indicate that ET-1, acting via $\mathrm{ET}_{\mathrm{A}}$ receptors, is a mechanism of pathophysiologic significance underlying neonatal HPVR. Development of this newborn mouse model of HPVR facilitates investigation of mechanisms underlying this important and severe disease entity in human infants. (Pediatr Res 57: 631-636, 2005)

ET-1, endothelin-1

\section{Abbreviations}

$\mathbf{E T}_{\mathbf{A}}$, endothelin-A receptor

HPVR, hypoxia-induced pulmonary vascular remodeling

PPHN, persistent pulmonary hypertension of the newborn

\%WT, percentage wall thickness of tunica media as compared to external diameter with considerable morbidity and mortality. Disorders such as bronchopulmonary dysplasia that affect extremely premature newborn infants are also associated with elevated pulmonary arterial pressures and pulmonary vascular remodeling (6). Congenital heart diseases associated with hypoxemia and/or increased pulmonary blood flow may also result in hypoxia- or high flow-induced pulmonary vascular remodeling $(7,8)$. In a newborn piglet model, increased vascular smooth muscle tone was the primary cause of elevated pulmonary pressure following 3-5 d of hypoxia exposure, while with longer hypoxia exposure (10-12 d), structural changes in the pulmonary arteries contributed to the elevated pulmonary arterial pressure (4).

ET-1 is a 21-amino acid polypeptide with strong vasoactive properties that acts via two major receptor isoforms in the vascular bed, $\mathrm{ET}_{\mathrm{A}}$ and $\mathrm{ET}_{\mathrm{B}}$. In the pulmonary artery, $\mathrm{ET}_{\mathrm{A}}$ receptors located predominantly on vascular smooth muscle cells mediate vasoconstriction, whereas $\mathrm{ET}_{\mathrm{B}}$ receptors that are located predominantly on endothelial cells mediate vasodilation (9). A subtype of the $\mathrm{ET}_{\mathrm{B}}$ receptor $\left(\mathrm{ET}_{\mathrm{B} 2}\right)$ present on 
vascular smooth muscle cells also mediates vasoconstriction (10). The biologic actions of ET-1 vary depending on age (11), vascular bed, dosage (12), and species (13). Specifically, ET-1 has many different functions in the fetus and neonate compared with the adult. ET-1 produces a positive inotropic response in neonatal myocardium but a negative response in the adult rat myocardium (14). Children have both higher peripheral levels of ET-1 and a higher density of binding sites for ET-1 compared with adults, even though the ratio of $\mathrm{ET}_{\mathrm{A}} / \mathrm{ET}_{\mathrm{B}}$ receptors is the same (70:30) (15). ET-1 levels are elevated in newborn infants with PPHN, are positively correlated with disease severity, and decline with resolution of disease in patients who do not require extracorporeal membrane oxygenation (ECMO) $(16,17)$.

Our previous studies showed that selective $\mathrm{ET}_{\mathrm{A}}$ receptor antagonists attenuate acute hypoxia-induced, but not group B streptococcal-induced, pulmonary hypertension in juvenile piglets (18). We have also shown that selective $\mathrm{ET}_{\mathrm{A}}$ receptor antagonists attenuate and reverse chronic hypoxic pulmonary hypertensive vascular and cardiac changes in adult rats $(19,20)$. However, pulmonary vascular remodeling is more severe in infant compared with adult animals after hypoxic exposure of the same magnitude (21). Neonatal chronic HPVR differs from adult HPVR with respect to extracellular matrix, pulmonary arterial smooth muscle structure, and vascular reactivity (22). The objectives of this study were to develop a newborn mouse model of HPVR, and to test the hypothesis that $\mathrm{ET}_{\mathrm{A}}$ blockade prevents and reverses HPVR in this model. Data from these studies will add to our understanding of the role of ET-1 in the pathogenesis of hypoxia-related pulmonary vascular disease, especially during the phase of rapid postnatal lung development.

\section{METHODS}

Experimental animals and animal care. The research protocol was approved by the Institutional Animal Care and Use Committee of the University of Alabama at Birmingham, and all care and handling of the animals was in accordance with National Institutes of Health guidelines. Timed pregnant C57BL/6 mice were obtained from Charles River Laboratories (Wilmington, MA).

Model development. Newborn C57BL/6 mouse pups and their mothers were exposed to normobaric hypoxia or room air from birth in a Plexiglas chamber. A Pro-Ox 110 oxygen controller (Bio-Spherix Ltd., Redfield, NY) servo-controlled the oxygen concentration to the set level by controlling the inflow of a mixture of nitrogen and oxygen gases. The mice were exposed to $14 \% \mathrm{O}_{2} \times 1 \mathrm{~d}, 13 \% \mathrm{O}_{2} \times 1 \mathrm{~d}$, followed by $12 \% \mathrm{O}_{2} \times 12 \mathrm{~d}$. Our preliminary studies showed that no HPVR occurred if the mice were exposed to $14 \% \mathrm{O}_{2}$ for $2 \mathrm{wk}$. If exposed to $10 \% \mathrm{O}_{2}$ from birth, excessive mortality was observed by $7 \mathrm{~d}$. At $12 \% \mathrm{O}_{2}$, a marked increase in mortality was seen only after $14 \mathrm{~d}$, with HPVR evident by $8-10$ d. $\mathrm{O}_{2}$ concentration (OM-100 oxygen analyzer, Newport Medical Instruments, Newport Beach, CA), humidity, temperature, and barometric pressure (Fisherbrand Digital Barometer, Fisher Scientific, Pittsburgh, PA) within the chamber were monitored continuously. Daily animal maintenance was carried out, with exposure of the animals to room air for $<10 \mathrm{~min}$ per day. A standard mouse pellet diet and water were provided ad libitum. After the completion of the period of hypoxia/normoxia exposure, the animals were euthanized and the thorax opened. The trachea was cannulated using a $24-\mathrm{G}$ angiocath and the lungs fixed in inflation using $10 \%$ formalin. The right ventricle was also perfused with formalin. After immersion in formalin for $24 \mathrm{~h}$, the samples were transferred to $70 \%$ ethanol, and both lungs were placed in a tissue cassette for paraffin embedding. Five-micron sections stained by hematoxylin and eosin $(\mathrm{H} \& \mathrm{E})$ or elastic stain were used for pulmonary vascular morphometry.

Drug preparation. Five milligrams of BQ 610 (Peptides International, Inc., Louisville, KY) were suspended in $1 \mathrm{~mL}$ of cottonseed oil and divided into multiple aliquots of $50-100 \mu \mathrm{L}$ each and frozen at $-20^{\circ} \mathrm{C}$. A fresh aliquot was used for each day of the exposure. The agent/vehicle was given intraperitoneally daily by microsyringe. A dose of $5 \mu \mathrm{L}$ was used for the first $5 \mathrm{~d}$ of life, followed by $10 \mu \mathrm{L}$ from d 6 to 10 and $15 \mu \mathrm{L}$ from d 11 to 14 . BQ610 was chosen as the $\mathrm{ET}_{\mathrm{A}}$ antagonist as we had previously noted its efficacy in the juvenile piglet model of hypoxia-induced pulmonary hypertension (18). Cottonseed oil was used as the vehicle and intraperitoneal administration was done to slow the release and obtain a prolonged effect. The dose of BQ610 (approximately $20 \mu \mathrm{g} / \mathrm{g} / \mathrm{d}$ body weight $=20 \mathrm{mg} / \mathrm{kg} / \mathrm{d}$ ) was empirically chosen based on the dosage by intraperitoneal injection in existing literature of other $\mathrm{ET}_{\mathrm{A}}$ blockers of similar potency (23), our previous experience with once-daily dosing of bosentan, a less potent nonselective endothelin blocker (24), and considerations of $\mathrm{IC}_{50}$ for $\mathrm{BQ} 610\left(\mathrm{IC}_{50}\right.$ for $\mathrm{ET}_{\mathrm{A}}$ binding of $0.64 \mathrm{nM}$ and 24,000 for $\mathrm{ET}_{\mathrm{B}}$ binding, indicating high selectivity for $\mathrm{ET}_{\mathrm{A}}$ receptors and lack of $\mathrm{ET}_{\mathrm{B}}$ effects even at higher than required dosage) (personal communication from Thukuba Research Institute, Banyu Pharmaceutical Co., Ltd).

Experimental design. This was a $2 \times 2$ factorial design, with animals exposed to either hypoxia or room air for $2 \mathrm{wk}$, while also being exposed to BQ-610 or vehicle. For the prevention study, hypoxia/room air exposure and BQ-610/vehicle began at birth and continued for $2 \mathrm{wk}$, whereas for the reversal study, neonatal mice were exposed to hypoxia or room air for the first week before initiating BQ-610 or vehicle, which was given for the next week. Animals were exposed by litter (each litter exposed to one set of conditions, e.g. hypoxia, BQ-610, prevention study), as randomization within a litter was not possible (skin marking did not prove permanent, and ear tagging is difficult in neonatal mice). Therefore, the sample size varied from group to group. A minimum sample size of six animals per group was the target for this study.

Pulmonary morphometry. Pulmonary vascular morphometry was performed by a modification of the techniques used by Rabinovitch et al. (25) and DiCarlo et al. (19). Five micron sections stained by $H \& E$ or elastin stain were used for pulmonary vascular morphometry using a Nikon Labophot microscope and a reticle eyepiece at $1000 \times$ magnification (oil immersion). The wall thickness (WT) of each artery was expressed as a percentage of the vessel diameter

\section{$\% \mathrm{WT}=100 \times(2 \times$ medial wall thickness $) /$ external diameter}

In each tissue section, the wall thickness and vessel diameter of at least 20 consecutive pulmonary arteries cut transversely (longer axis $<50 \%$ greater than shorter axis) were determined along two axes perpendicular to each other. Pulmonary arteries were defined as vessels that accompanied airways (veins are interlobular). Vessels $<20 \mu \mathrm{m}$ in external diameter were not considered for analysis, as wall thickness is not uniform in these vessels. All morphometric analysis was carried out by a single examiner masked to the group assignment.

Estimation of right ventricular hypertrophy. Transverse sections of the heart just inferior to the mitral valve leaflet were evaluated for right ventricle $(\mathrm{RV})$ free wall and left ventricle (LV) free wall thickness using a reticle eyepiece at $40 \times$ magnification. The calculated $R V / L V$ ratio was considered an index of RV hypertrophy. This procedure of comparison of RV to LV free wall thickness was used, as the more conventional technique comparing RV to LV + septal weight ratio could not be used in the extremely small newborn mouse heart.

\section{RESULTS}

Development of the model. Newborn mice were acclimatized to hypoxia by exposure to $14 \% \mathrm{O}_{2} \times 1 \mathrm{~d}, 13 \% \mathrm{O}_{2} \times 1 \mathrm{~d}$, followed by $12 \% \mathrm{O}_{2} \times 12 \mathrm{~d}$. Despite this, exposure of newborn mice to hypoxia was initially associated with increased mortality in some litters compared with room air controls (initial mortality-room air: 15\%, room air + BQ-610: 20\%, hypoxia: 40\%, hypoxia + BQ-610: 35\%). This increased mortality was nearly always in the first $3 \mathrm{~d}$ and probably related to maternal neglect rather than hypoxia per se, as the normal nesting and feeding behaviors of the mother were observed to be diminished in the litters that demonstrated increased mortality, and pups that died did not have the stomach distended with milk. Mortality was subsequently significantly reduced in both groups (current mortality-10\% in room air and $20 \%$ in hypoxia groups; comparable to that in routine nonexperimental conditions) by use of experienced dams, reduction in handling, addition of extra nesting material, and a high-fat breeding diet. 
We have presented the data only from the recent litters with the lower mortality. Surviving hypoxia exposed pups were active but were smaller than room air controls. Hypoxic pups weighed approximately (median) $1 \mathrm{~g}$ on d $3,2 \mathrm{~g}$ on $\mathrm{d} 7,3.2 \mathrm{~g}$ on $\mathrm{d} 10$, and $5 \mathrm{~g}$ on $\mathrm{d} 14$, whereas normoxic pups weighed approximately $50 \%$ more: $1.5 \mathrm{~g}$ on d $3,3 \mathrm{~g}$ on d $7,5 \mathrm{~g}$ on d 10 , and $7 \mathrm{~g}$ on $\mathrm{d} 14$. Administration of BQ-610 did not prevent the growth retardation (data not shown).

Pulmonary vascular morphometry. A total of 64 mouse pups were evaluated (10-20 per group). Exposure to chronic hypoxia increased thickness of those pulmonary arteries smaller than $100 \mu \mathrm{m}$ external diameter (Figs. 1, 2). The magnitude of the hypoxia-induced increase was approximately $43 \%$ (median) when all pulmonary arteries $(20-300 \mu \mathrm{m})$ were considered. Smaller (resistance) arteries showed the greatest increase in thickness with hypoxia: the magnitude of increase was $47 \%$ in arteries $20-50 \mu \mathrm{m}$ diameter $(p<0.05$ versus room air), 37\% for arteries 50-99 $\mu \mathrm{m}$ diameter $(p<0.05)$, and $28 \%$ for arteries 100-200 $\mu \mathrm{m}$ diameter (NS) (Fig. 2). Smaller pulmonary arteries also had proportionately thicker walls compared with larger vessels, even under normoxic conditions (Fig. 2).

Administration of BQ-610 prevented and partially reversed hypoxia-induced wall thickening (Figs. 1, 2). BQ-610 completely prevented the hypoxia-induced thickening of pulmonary arteries $20-100 \mu \mathrm{m}$ (there were an insufficient number of vessels at $100-199 \mu \mathrm{m}$ for statistical significance, although the trend was similar), but the effect of reversal was significant only in the smaller arteries $(20-50 \mu \mathrm{m})$ (Fig. 2). The size distribution of pulmonary arteries was not significantly altered by hypoxia or administration of BQ-610 (i.e. a similar proportion of pulmonary arteries were $20-50 \mu \mathrm{m}$ or $50-99 \mu \mathrm{m}$ in external diameter) (Fig. 3). BQ-610 had no effect on pulmonary arteries of room air mice (only the data for the room air BQ-610 prevention group are presented, as the room air BQ610 reversal group was very similar). There were no effects of the vehicle on medial wall thickness when control animals given vehicle were compared with those not given vehicle, either during room air or hypoxia exposure (data not shown).

Right ventricle to left ventricle wall thickness ratio. Hypoxia increased the relative thickness of the RV free wall compared with the LV free wall. BQ-610 completely prevented this increase, but did not reverse it significantly when initiated after one week of hypoxia exposure (Fig. 4). BQ-610 did not affect the ventricular wall thickness ratios in the room air exposed animals.

\section{DISCUSSION}

The present study describes the development of a newborn mouse model of chronic hypoxia-induced pulmonary vascular remodeling, and demonstrates that endothelin-A receptor blockade prevents and partially reverses the pulmonary vascular remodeling in this animal model. These observations support our hypothesis that ET-1 plays a role in the development of hypoxia-induced pulmonary vascular remodeling via $\mathrm{ET}_{\mathrm{A}}$ activation. Our previous work (18) in a neonatal piglet model of acute hypoxia demonstrated that treatment with selective
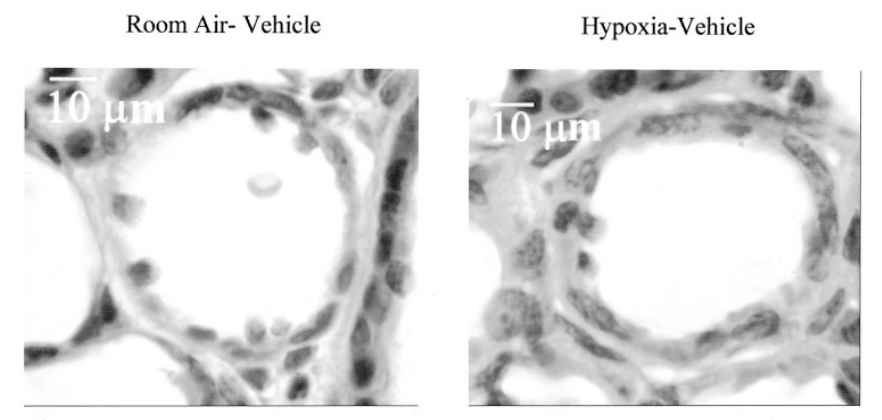

Hypoxia- BQ-610 Prevention

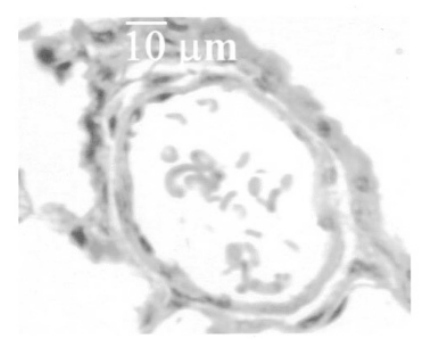

Figure 1. Representative photomicrographs of pulmonary arteries from mice exposed from birth to $2 \mathrm{wk}$ of age to either room air or hypoxia $\left(12 \% \mathrm{O}_{2}\right)$ in combination with either vehicle or BQ-610 (selective endothelin-A receptor blocker). Vehicle or BQ-610 was given either from birth (prevention) or for the postnatal second week (reversal study). The media thickens with chronic exposure to hypoxia, and this is prevented and partially reversed with BQ-610.
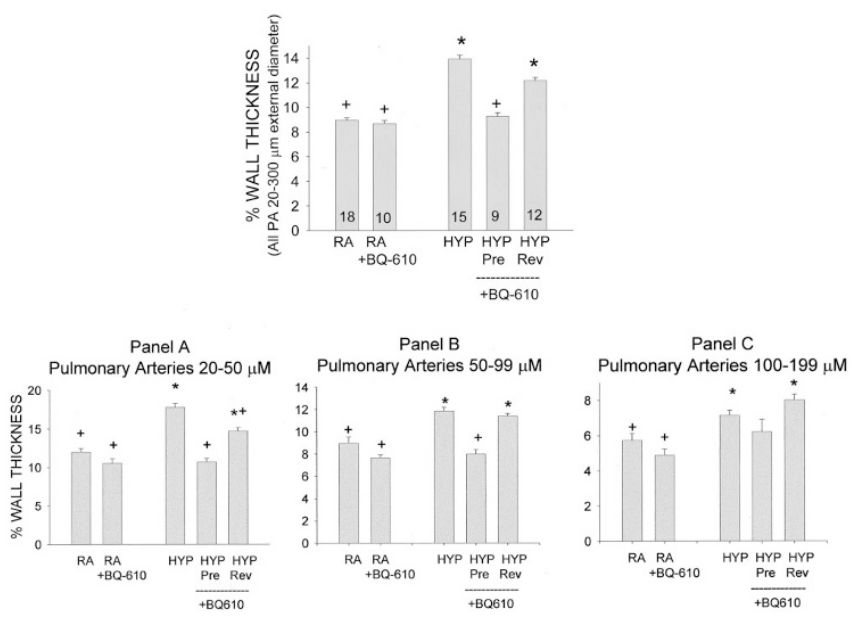

Figure 2. Top panel shows the effect of chronic hypoxia $\left(12 \% \mathrm{O}_{2} \times 2 \mathrm{wk}\right)$ on medial wall thickness of pulmonary arteries (PA) 20-300 $\mu \mathrm{m}$ external diameter in newborn mice (mean $\pm \mathrm{SE} ; n=64$ mice total, $n$ for each group at base of bar; 20 vessels/mouse; $p<0.001$ by ANOVA; * $p<0.05 v s \mathrm{RA} ;+p$ $<0.05$ vs HYP by Tukey's test). Bottom panels $A, B$, and $C$ show the effects in PA of different sizes. Panel A: arteries 20-50 $\mu \mathrm{m}$ diameter, $n=455$ vessels (40-180 /group); Panel B: arteries 50-99 $\mu \mathrm{m}$ diameter, $n=525$ vessels (45-190/group); Panel $C$ : arteries 100-199 $\mu \mathrm{m}$ diameter, $n=180$ vessels (15-54/ group). Animals were exposed to chronic hypoxia (HYP) or room air $(R A)$ for $2 \mathrm{wk}$ in combination with either $\mathrm{ET}_{\mathrm{A}}$ blocker (BQ-610) or vehicle. BQ-610 was able to prevent (pre) and partially reverse (rev) the thickening of the tunica media that occurred with chronic hypoxic exposure. The effect of BQ-610 on prevention (pre) and partial reversal (rev) was most evident in the smaller (resistance) pulmonary arteries $<100 \mu \mathrm{m}$ external diameter. 


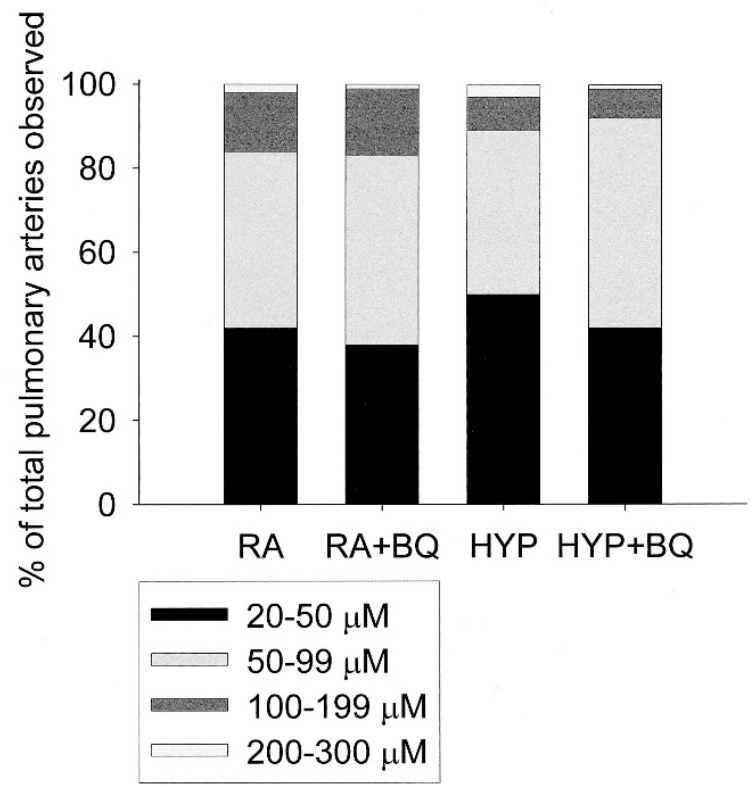

Figure 3. Pulmonary artery size distribution in newborn mice exposed to hypoxia or room air, in combination with either BQ-610 (prevention group) or vehicle. No significant differences in the size distribution were observed by comparison of proportions.

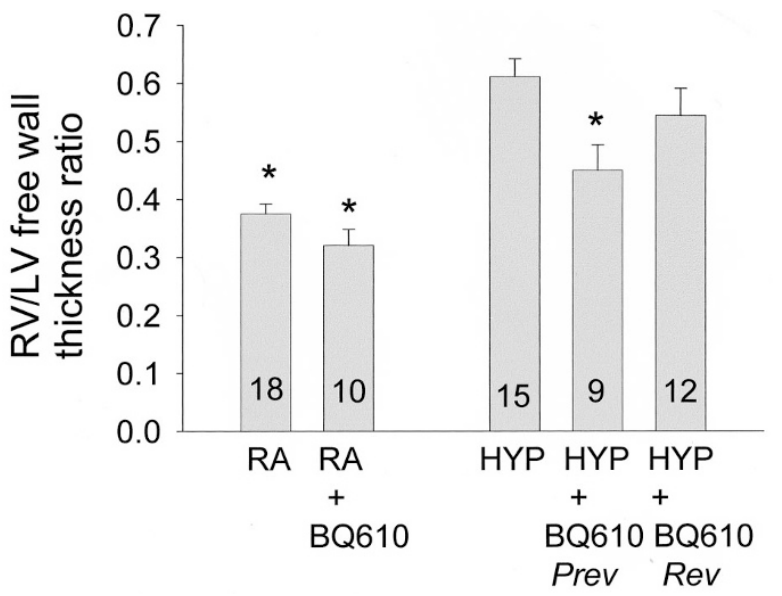

Figure 4. Effect on neonatal mouse heart RV/LV ratio of room air $(R A)$ or chronic hypoxia $\left(H Y P ; 12 \% \mathrm{O}_{2} \times 2 \mathrm{wk}\right)$ in combination with $\mathrm{ET}_{\mathrm{A}}$ blockade with BQ-610 or vehicle (mean $\pm \mathrm{SE} ; n$ at base of bar; $p<0.01$ by two-way ANOVA for HYP versus RA and for vehicle versus BQ-610; * $p<0.05$ versus HYP-vehicle). Hypoxia leads to an increase in relative thickness of the right ventricle compared with the left ventricle, and this is prevented (BQ-610 Pre) but not reversed by BQ-610 (BQ-610 Rev).

$\mathrm{ET}_{\mathrm{A}}$ blockers (BQ-610 and EMD 122946) decreases pulmonary arterial pressures and pulmonary vascular resistance, without significantly affecting systemic arterial pressures or vascular resistance. Therefore, selective $\mathrm{ET}_{\mathrm{A}}$ blockers are effective in attenuating both acute (vasoconstriction) and chronic effects of hypoxia (remodeling) on the pulmonary vasculature.

The newborn mouse has many advantages as a model for hypoxia-induced neonatal pulmonary vascular remodeling. Lung development in the human infant from wk 24 of gestation through the first $2 \mathrm{y}$ of age closely parallels lung development of mice in the first two postnatal weeks of age $(26,27)$, indicating that this model is appropriate for the evaluation of pulmonary vascular development and remodeling in the infant. The main strength of this model is that modulation of the effects of chronic hypoxia on the developing pulmonary vasculature by expression of specific genes or their absence can be determined using transgenic (either "knockout" or "overexpression") mice. Also, many antibodies and probes are commercially available for use in mice. A larger sample size for lower cost is also possible in view of the many pups in one litter. The small size of the newborn mouse is also an advantage when very expensive compounds such as BQ-610 have to be administered for a prolonged duration.

There are, however, some limitations to the newborn mouse model. As in all animal models, it is possible that, due to interspecies differences, this model may not be directly extrapolated to human neonates, especially as chronic alveolar hypoxia as used in this model is not the etiology of pulmonary hypertension in human neonates. Also, due to age-specific effects, it is possible that fetal hypoxia, hypoxia in the first $2 \mathrm{~d}$ after birth, and hypoxia starting a week after birth would all have different physiologic effects. However, differences in hypoxia-induced vascular remodeling (structural effects) are difficult to ascertain with brief hypoxia exposures of less than a week in this model and, hence, age-specific effects are difficult to determine. Hemodynamic measurements are difficult, and isolation of pulmonary vascular cells from newborn mice for investigation of cellular mechanisms is technically challenging. Chronic hypoxic exposure in the developing animal (unlike the adult animal) leads to growth retardation, and concomitant impairment of lung alveolar development (and lung vascular growth) may occur $(28,29)$. However, it is not possible to determine what degree of remodeling is directly due to hypoxia per se and how much is due to growth restriction induced by hypoxia.

$\mathrm{ET}_{\mathrm{A}}$ antagonists prevent fetal or neonatal pulmonary vascular remodeling in other fetal/neonatal animal models. Ivy et al. (30) demonstrated in an ovine fetal preparation of pulmonary hypertension induced by ductal ligation that preventive treatment with BQ-123 attenuated pulmonary hypertension and pulmonary vascular remodeling. Perreault et al. (31) showed that an orally active nonpeptidic $\mathrm{ET}_{\mathrm{A}}$ antagonist (TBC3711) decreased pulmonary vascular changes induced by chronic hypoxia in the neonatal piglet, when administered from $\mathrm{d} 3$ to d 14 of the hypoxic exposure.

In the current study, the effect of hypoxia was most evident in the smaller "resistance" pulmonary arteries in the newborn mice, which suggests that chronic hypoxia leads to pulmonary hypertension and RV hypertrophy in this animal model in a manner similar to that in human neonates (1) and other neonatal animal models $(30,31)$. Selective $\mathrm{ET}_{\mathrm{A}}$ antagonism attenuated the increase in vessel wall thickness in the same vessels that were most affected by hypoxia, suggesting that this antagonism was specific to the effects of hypoxia. The size distribution of vessels in hypoxia exposed (and hypoxia $+\mathrm{ET}_{\mathrm{A}}$ blocker-exposed animals) was similar to that of room airexposed animals, indicating that during the 2 wk of exposure to hypoxia, there was no significant trend for the development of pulmonary arteries of smaller external diameter. The increased 
pulmonary arterial medial wall thickness may be secondary to smooth muscle cell hyperplasia, hypertrophy, or accumulation of extracellular matrix (32). There is evidence that hypoxia leads to proliferation of specific subpopulations of smooth muscle cells (33) and adventitial fibroblasts (34) in the newborn calf model. The precise mechanisms responsible for the increased thickness of the media with hypoxia remain to be investigated in the mouse model.

Previous work from our laboratory showed that chronic hypoxic exposure increases pulmonary arterial pressure, plasma ET-1 levels, and gene transcript levels for ET-1 and the $\mathrm{ET}_{\mathrm{A}}$ and $\mathrm{ET}_{\mathrm{B}}$ receptors in the lung, but not in the great vessels or any other organ (35). In another study, mice expressing prepro-endothelin-1 promoter-luciferase (PPET-1/LUC) reporter transgenes were exposed to hypoxia for $24 \mathrm{~h}$ (36). LUC expression was increased 6-fold in pulmonary tissue but only 2 -fold in other tissues. In situ hybridization revealed the strongest transgene expression in the pulmonary vasculature and bronchiolar epithelium. Therefore, hypoxia induces PPET-1, as well as ET receptors in the lung in a selective manner. ET $_{\mathrm{A}}$ antagonists, by inhibiting the effect of elevated levels of ET-1 during hypoxic conditions, may not only attenuate vasoconstriction and vascular remodeling by their effects on $\mathrm{ET}_{\mathrm{A}}$ receptors, but may also augment vasodilation by the unopposed action of ET-1 on $\mathrm{ET}_{\mathrm{B}}$ receptors, leading to an increased release of nitric oxide (37). It is probable that $\mathrm{ET}_{\mathrm{B} 2}$ (constrictor) receptors do not play a major role in HPVR, as selective $\mathrm{ET}_{\mathrm{A}}$ blockade was able to completely prevent HPVR. Only partial reversal of HPVR and cardiac remodeling was noted when $\mathrm{ET}_{\mathrm{A}}$ blockade was initiated after the first week. These results are similar to those noted in our previous studies with selective $\mathrm{ET}_{\mathrm{A}}$ blockers in adult rats $(19,20)$.

There have been some preliminary studies on the therapeutic efficacy of selective $\mathrm{ET}_{\mathrm{A}}$ antagonists in human infants. Two small studies of a total of 10 children noted improvement in pulmonary hemodynamics after administration of BQ-123 for postoperative pulmonary hypertension after corrective surgery for congenital heart disease $(38,39)$. However, there have been no randomized controlled trials evaluating $\mathrm{ET}_{\mathrm{A}}$ antagonists in neonates, infants, or children, although randomized trials in adults using nonselective ET antagonists in primary pulmonary hypertension (40) and selective $\mathrm{ET}_{\mathrm{A}}$ antagonists in pulmonary hypertension secondary to heart failure (41) have shown benefit despite some adverse effects such as abnormal hepatic function. Our study demonstrating that selective $\mathrm{ET}_{\mathrm{A}}$ blockers are effective in both prevention and reversal of HPVR therefore has therapeutic significance and indicates that selective $\mathrm{ET}_{\mathrm{A}}$ antagonists may be candidates for clinical trials in infants with preexisting abnormal pulmonary vascular remodeling, such as infants with PPHN or cor pulmonale.

In conclusion, this study has demonstrated the usefulness of a newborn mouse model for the evaluation of HPVR, and has shown that selective $\mathrm{ET}_{\mathrm{A}}$ blockers are effective in preventing and in partially reversing HPVR. Further studies are in progress to determine the effects of hypoxic exposure on gene expression in the newborn mouse lung, and to determine whether $\mathrm{ET}_{\mathrm{A}}$ blockade is able to prevent and reverse these hypoxia-induced alterations. The interactions of $\mathrm{ET}_{\mathrm{A}}$ blockade with other signaling pathways are also being investigated using transgenic mice. This may enable the identification of new therapeutic targets and new strategies for the management of pulmonary vascular remodeling in the neonate and infant.

\section{REFERENCES}

1. Murphy JD, Vawter GF, Reid LM 1984 Pulmonary vascular disease in fatal meconium aspiration. J Pediatr 104:758-762

2. Drummond WH, Bissonnette JM 1978 Persistent pulmonary hypertension in the neonate: development of an animal model. Am J Obstet Gynecol 131:761-763

3. Stenmark KR, Fasules J, Hyde DM, Voelkel NF, Henson J, Tucker A, Wilson H, Reeves JT 1987 Severe pulmonary hypertension and arterial adventitial changes in newborn calves at 4,300 m. J Appl Physiol 62:821-830

4. Fike CD, Kaplowitz MR 1994 Effect of chronic hypoxia on pulmonary vascular pressures in isolated lungs of newborn pigs. J Appl Physiol 77:2853-2862

5. Walsh-Sukys MC 1993 Persistent pulmonary hypertension of the newborn. The black box revisited. Clin Perinatol 20:127-143

6. Goodman G, Perkin RM, Anas NG, Sperling DR, Hicks DA, Rowen M 1988 Pulmonary hypertension in infants with bronchopulmonary dysplasia. J Pediatr 112:67-72

7. Hoffmeister HM, Apitz J, Hoffmeister HE, Fischbach H 1981 The correlation between blood pressure and morphometric findings in children with congenital heart disease and pulmonary hypertension. Basic Res Cardiol 76:647-656

8. Steinhorn RH, Fineman JR 1999 The pathophysiology of pulmonary hypertension in congenital heart disease. Artif Organs 23:970-974

9. Ziegler JW, Ivy DD, Kinsella JP, Abman SH 1995 The role of nitric oxide, endothelin, and prostaglandins in the transition of the pulmonary circulation. Clin Perinatol 22:387-403

10. Ortega Mateo A, de Artinano AA 1997 Highlights on endothelins: a review. Pharmacol Res 36:339-351

11. Wong J, Vanderford PA, Fineman JR, Chang R, Soifer SJ 1993 Endothelin-1 produces pulmonary vasodilation in the intact newborn lamb. Am J Physiol 265:H1318-H1325

12. Bradley LM, Czaga JF, Goldstein RE 1990 Circulatory effects of endothelin in newborn piglets. Am J Physiol 259:H1613-H1617

13. Barnard JW, Barman SA, Adkins WK, Longenecker GL, Taylor AE 1991 Sustained effects of endothelin-1 on rabbit, dog, and rat pulmonary circulations. Am J Physiol 261:H479-H486

14. Sekine T, Kusano H, Nishimaru K, Tanaka Y, Tanaka H, Shigenobu K 1999 Developmental conversion of inotropism by endothelin I and angiotensin II from positive to negative in mice. Eur J Pharmacol 374:411-415

15. Giannessi D, Del Ry S, Andreassi MG, Nardini V, Pelosi G, Colombo MG, Biagini A 1999 High density of endothelin binding sites in the hearts of infants and children. Life Sci 64:697-705

16. Kumar P, Kazzi NJ, Shankaran S 1996 Plasma immunoreactive endothelin-1 concentrations in infants with persistent pulmonary hypertension of the newborn. Am J Perinatol 13:335-341

17. Rosenberg AA, Kennaugh J, Koppenhafer SL, Loomis M, Chatfield BA, Abman SH 1993 Elevated immunoreactive endothelin-1 levels in newborn infants with persistent pulmonary hypertension. J Pediatr 123:109-114

18. Ambalavanan N, Philips JB III, Bulger A, Oparil S, Chen YF 2002 Endothelin-A receptor blockade in porcine pulmonary hypertension. Pediatr Res 52:913-921

19. DiCarlo VS, Chen SJ, Meng QC, Durand J, Yano M, Chen YF, Oparil S 1995 ETA-receptor antagonist prevents and reverses chronic hypoxia-induced pulmonary hypertension in rat. Am J Physiol 269:L690-L697

20. Chen SJ, Chen YF, Opgenorth TJ, Wessale JL, Meng QC, Durand J, DiCarlo VS, Oparil S 1997 The orally active nonpeptide endothelin A-receptor antagonist A-127722 prevents and reverses hypoxia-induced pulmonary hypertension and pulmonary vascular remodeling in Sprague-Dawley rats. J Cardiovasc Pharmacol 29:713-725

21. Rabinovitch M, Gamble WJ, Miettinen OS, Reid L 1981 Age and sex influence on pulmonary hypertension of chronic hypoxia and on recovery. Am J Physiol 240:H62H72

22. Kelly DA, Hislop AA, Hall SM, Haworth SG 2002 Correlation of pulmonary arterial smooth muscle structure and reactivity during adaptation to extrauterine life. J Vasc Res 39:30-40

23. Ebihara I, Nakamura T, Tomino Y, Koide H 1997 Effect of a specific endothelin receptor A antagonist and an angiotensin-converting enzyme inhibitor on glomerular mRNA levels for extracellular matrix components, metalloproteinases (MMP) and a tissue inhibitor of MMP in aminonucleoside nephrosis. Nephrol Dial Transplant 12:1001-1006

24. Chen SJ, Chen YF, Meng QC, Durand J, Dicarlo VS, Oparil S 1995 Endothelinreceptor antagonist bosentan prevents and reverses hypoxic pulmonary hypertension in rats. J Appl Physiol 79:2122-2131

25. Rabinovitch M, Gamble W, Nadas AS, Miettinen OS, Reid L 1979 Rat pulmonary circulation after chronic hypoxia: hemodynamic and structural features. Am J Physiol 236:H818-H827

26. Burri P 1997 Structural aspects of prenatal and postnatal development and growth for the lung. In: McDonald JA (ed) Lung Growth and Development. Dekker, New York, pp $1-35$

27. Amy RW, Bowes D, Burri PH, Haines J, Thurlbeck WM 1977 Postnatal growth of the mouse lung. J Anat 124:131-151 
28. Vicencio AG, Eickelberg O, Stankewich MC, Kashgarian M, Haddad GG 2002 Regulation of TGF-beta ligand and receptor expression in neonatal rat lungs exposed to chronic hypoxia. J Appl Physiol 93:1123-1130

29. Sekhon HS, Thurlbeck WM 1996 Lung morphometric changes after exposure to hypobaria and/or hypoxia and undernutrition. Respir Physiol 106:99-107

30. Ivy DD, Parker TA, Zeigler JW, Galan HL, Kinsella JP, Tuder RM, Abman SH 1997 Prolonged endothelin A receptor blockade attenuates chronic pulmonary hypertension in the ovine fetus. J Clin Invest 99:1179-1186

31. Perreault T, Berkenbosch JW, Barrington KJ, Decker ER, Wu C, Brock TA, Baribeau J 2001 TBC3711, an ET(A) receptor antagonist, reduces neonatal hypoxia-induced pulmonary hypertension in piglets. Pediatr Res 50:374-383

32. Rabinovitch M 1996 Cell-extracellular matrix interactions in the ductus arteriosus and perinatal pulmonary circulation. Semin Perinatol 20:531-541

33. Wohrley JD, Frid MG, Moiseeva EP, Orton EC, Belknap JK, Stenmark KR 1995 Hypoxia selectively induces proliferation in a specific subpopulation of smooth muscle cells in the bovine neonatal pulmonary arterial media. J Clin Invest 96:273-281

34. Das M, Dempsey EC, Reeves JT, Stenmark KR 2002 Selective expansion of fibroblast subpopulations from pulmonary artery adventitia in response to hypoxia. Am J Physiol Lung Cell Mol Physiol 282:L976-L986

35. Li H, Chen SJ, Chen YF, Meng QC, Durand J, Oparil S, Elton TS 1994 Enhanced endothelin-1 and endothelin receptor gene expression in chronic hypoxia. J Appl Physiol 77:1451-1459
36. Aversa CR, Oparil S, Caro J, Li H, Sun SD, Chen YF, Swerdel MR, Monticello TM, Durham SK, Minchenko A, Lira SA, Webb ML 1997 Hypoxia stimulates human preproendothelin-1 promoter activity in transgenic mice. Am J Physiol 273:L848 L855

37. Ivy DD, Kinsella JP, Abman SH 1994 Physiologic characterization of endothelin A and $\mathrm{B}$ receptor activity in the ovine fetal pulmonary circulation. J Clin Invest 93:2141-2148

38. Prendergast B, Newby DE, Wilson LE, Webb DJ, Mankad PS 1999 Early therapeutic experience with the endothelin antagonist BQ-123 in pulmonary hypertension after congenital heart surgery. Heart 82:505-508

39. Schulze-Neick I, Li J, Reader JA, Shekerdemian L, Redington AN, Penny DJ 2002 The endothelin antagonist BQ123 reduces pulmonary vascular resistance after surgical intervention for congenital heart disease. J Thorac Cardiovasc Surg 124:435-441

40. Rubin LJ, Badesch DB, Barst RJ, Galie N, Black CM, Keogh A, Pulido T, Frost A, Roux S, Leconte I, Landzberg M, Simonneau G 2002 Bosentan therapy for pulmonary arterial hypertension. N Engl J Med 346:896-903

41. Givertz MM, Colucci WS, LeJemtel TH, Gottlieb SS, Hare JM, Slawsky MT, Leie CV, Loh E, Nicklas JM, Lewis BE 2000 Acute endothelin A receptor blockade causes selective pulmonary vasodilation in patients with chronic heart failure. Circulation 101:2922-2927 